Cuadros, G.M. 'Ecoturismo' o la 'cuadratura del círculo': mas que un tinte verde a la actividad económica del turismo. Anais do VIII Congresso Nacional de Ecoturismo e do IV Encontro Interdisciplinar de Ecoturismo em Unidades de Conservação. Revista Brasileira de Ecoturismo, São Paulo, v.4, n.4, 2011, p. 588.

\title{
‘ECOTURISMO’ O LA ‘CUADRATURA DEL CÍRCULO’: MAS QUE UN TINTE VERDE A LA ACTIVIDAD ECONÓMICA DEL TURISMO
}

\author{
Gregorio Mesa Cuadros* \\ *Universidad Nacional de Colombia \\ E-mail: gmesac@bt.unal.edu.co
}

Nadie duda de las consecuencias económicas o crematísticas del incremento de las actividades turísticas pero la discusión que aquí nos ocupa es precisar si esta actividad es sostenible, si puede llegar 0 puede serlo. Por ello, podemos indicar la necesidad de hablar en serio de "ecoturismo" para que no quede solo como una falacia o como solo un tinte verde para una actividad que por sí misma, es depredadora y contaminadora. En los últimos tiempos está de moda de teñirse de verde para estar en el estándar internacional o nacional de que una determinada actividad humana que desarrollamos es amigable con el ambiente. Pero no siempre, esa asociación entre ser verde y realizar una actividad económica es congruente, responsable o conservacionista del ambiente o de su uso cuidadoso. Por ello se deben mirar los aspectos concretos de esta clase de denominación, en últimas, precisar si es posible hablar de "ecoturismo", conceptualmente hablando. La mayoría de las prácticas denominadas ecoturísticas no lo son porque están asociadas a actividades productivas que para ser económicamente viables y rentables, requieren usar indiscriminada y exageradamente recursos naturales o elementos o componentes del ambiente. En efecto, la publicidad turística enuncia y promueve mayores consumos, por lo tanto, mayores presiones al ambiente y a los ecosistemas y, seguramente, menores consideraciones de cuidado y conservación que son el elemento central de la protección tanto del entorno urbano y natural (BLANQUER, 2000), que desde nuestra perspectiva reconfigura la genérica protección ambiental. Las diversas teorías conservacionistas (ecologistas y ambientalistas) parten de la idea general de restringir los consumos que, convertidos en huella ambiental insostenible, es decir los consumos exosomáticos, son esencialmente culturales, asociados a prácticas de sobreconsumo de la sociedad capitalista contemporánea que no quiere poner límite o freno a las prácticas de apropiación de la naturaleza y, las normas de restricción o de límite, de carácter ambiental, si existen, se erosionan o restringen hasta hacer imposible la concreción de la sostenibilidad. ¿Cómo hacer, entonces, para que se pueda hablar de "ecoturismo" sin caer en la falacia del error conceptual y de la contradicción en los términos turismo y conservación? En este escrito presentamos tres momentos para contribuir a este debate. El primero, indica una concepción de ambiente y una teoría de la apropiación de la naturaleza. La segunda desarrolla el concepto de huella ambiental sostenible para precisar la idea de conservación. La tercera establece las relaciones teóricas y prácticas de las actividades productivas asociadas al turismo y las posibilidades o no de concretar el principio de sostenibilidad.

\section{Bibliografía}

Blanquer, David. 2000. "La ordenación jurídica de la calidad del turismo". En: Sosa Wagner, Francisco (coord.) 2000. El derecho administrativo en el umbral del siglo XXI. Homenaje al profesor Ramón Martín Mateo. Tomo III. Valencia: Tirant Lo Blanch, pág. 3121 a 3174.

Palabras-Clave: Ecoturismo; Sostenibilidad; Conservación. 